\title{
Considerations for expanding
} community exercise programs incorporating a healthcare-recreation partnership for people with balance and mobility limitations: a mixed methods evaluation

\author{
Nancy M. Salbach $\left.{ }^{1,2^{*}} \mathbb{(}\right)$, Jo-Anne Howe ${ }^{1,2}$, Diem Baldry ${ }^{1}$, Saira Merali ${ }^{1}$ and Sarah E. P. Munce ${ }^{2}$
}

\begin{abstract}
Objective: To increase access to safe and appropriate exercise for people with balance and mobility limitations, community organizations have partnered with healthcare providers to deliver an evidence-based, task-oriented group exercise program in community centers in Canada. We aimed to understand challenges and solutions to implementing this program model to inform plans for expansion.

Results: At a 1-day meeting, 53 stakeholders (healthcare/recreation personnel, program participants/caregivers, researchers) identified challenges to program implementation that were captured by seven themes: Resources to deliver the exercise class (e.g., difficulty finding instructors with the skills to work with people with mobility limitations); Program marketing (e.g., to foster healthcare referrals); Transportation (e.g., particularly from rural areas); Program access (e.g., program full); Maintaining program integrity; Sustaining partnerships (i.e., with healthcare partners); and Funding (e.g., to deliver program or register). Stakeholders prioritized solutions to form an action plan. A survey of individuals supervising 28 programs revealed that people with stroke, acquired brain injury, multiple sclerosis, and Parkinson's disease register at $95-100 \%$ of centers. The most prevalent issues with program fidelity across centers were not requiring a minimum level of walking ability (32\%), class sizes exceeding 12 (21\%), and instructor-to-participant ratios exceeding 1:4 (19\%). Findings provide considerations for program expansion.
\end{abstract}

Keywords: Community, Task-oriented exercise, Balance, Mobility, Spread, Scale-up

\section{Introduction}

Many chronic health conditions, such as stroke and multiple sclerosis, result in persistent balance and mobility limitations [1-3]. Balance and mobility limitations contribute to functional dependence [1] and physical inactivity [4] which can further diminish health [1, 57]. Community-based exercise programs (CBEPs) that involve a healthcare professional have emerged in the United Kingdom [8-13], Australia [14], Italy [15], Canada

\footnotetext{
*Correspondence: nancy.salbach@utoronto.ca

${ }^{1}$ Department of Physical Therapy, University of Toronto, 160-500

University Avenue, Toronto, ON M5G 1V7, Canada

Full list of author information is available at the end of the article
}

[16], and the United States [17]. These programs can facilitate safe exercise participation for people with disabilities to help mitigate the negative consequences of balance and mobility limitations [12-16, 18].

In Canada, a group, task-oriented, CBEP incorporating a healthcare-recreation partnership (CBEP-HRP) called "Together in Movement and Exercise" $\left(\mathrm{TIME}^{\mathrm{TM}}\right.$ ) has been developed $[16,19]$. This program has been proven safe and appropriate for people with balance and mobility limitations who can walk at least $10 \mathrm{~m}$ independently and have sufficient cognitive and communication ability to function in a group setting [16]. In the TIME ${ }^{\mathrm{TM}}$ partnership, healthcare professionals, typically physical 
therapists, train and support fitness instructors to deliver the exercise program in community centers run by recreation organizations. The partnership was designed to maintain program quality and safety and support participant referral.

$\mathrm{TIME}^{\mathrm{TM}}$ involves a $1-\mathrm{h}$ exercise class provided twice a week for 12 weeks. Classes involve seated warm-up and cool-down exercises, and practice of functional exercises (e.g., sit-to-stand, modified lunges, step-ups, walking), with standardized progressions, designed to improve balance and mobility. A minimum instructor-plus-volunteer-to-participant ratio of $1: 4$ is required to maintain adequate supervision and exercise progression [16]. Family members are invited to assist during the class if needed.

After a pilot study demonstrated the safety, feasibility, and potential benefit of the TIME ${ }^{\mathrm{TM}}$ model [16], a toolkit [20] that includes exercise guidelines and space/equipment requirements to run the program was developed. Using this toolkit, coordinators within stroke networks and regional health authorities facilitated spread of the $\mathrm{TIME}^{\mathrm{TM}}$ program to 28 community centers in Ontario and British Columbia, Canada by 2014. Although the ultimate goal of the TIME $^{\mathrm{TM}}$ model was to enable longterm access to safe and beneficial exercise for people with balance and mobility limitations, the extent to which the $\mathrm{TIME}^{\mathrm{TM}}$ program was being delivered as designed, and the feasibility of sustaining the program were unclear. Thus, the aim of this study was to identify challenges with initial and sustained implementation of the TIME ${ }^{\text {TM }}$ program model and solutions as perceived by program stakeholders. Results are expected to inform action plans to improve access to group, task-oriented, CBEP-HRPs for people with balance and mobility limitations.

\section{Main text Methods}

A 1-day stakeholder meeting and two follow-up surveys were undertaken. Seventy-seven individuals from academic, healthcare, and recreation sectors from across Canada who had experience with the $\mathrm{TIME}^{\mathrm{TM}}$ program or a similar program were invited to participate in the stakeholder meeting in May 2014. Recreation coordinators obtained permission from $\mathrm{TIME}^{\mathrm{TM}}$ exercise participants and caregivers to contact them with an invitation to participate.

Prior to the meeting, individuals were asked to document challenges, facilitators and strategies to implementing or participating in CBEPs using a standardized form (Additional file 1). Forms were submitted at meeting registration. Data were synthesized and presented during the meeting (agenda in Additional file 2). Morning meeting activities involved sharing of experiences with delivering or participating in the $\mathrm{TIME}^{\mathrm{TM}}$ program, research evidence supporting group, task-oriented training, and funding and policy issues affecting program expansion. In the afternoon, participants, seated by stakeholder group, were asked to identify and report on the two most important challenges with implementing the TIME $^{\mathrm{TM}}$ model. Meeting facilitators (authors NMS \& DB) documented the challenges. Each participant was then asked to vote for his/her top two challenges using a ballot that was color-coded by stakeholder group. After collecting the ballots, each stakeholder group was assigned one challenge and asked to identify and report on strategies to address the challenge. The strategies were documented. Immediately following the meeting, participants were invited to complete an online questionnaire to rate the level of priority of strategies as: not a priority, low priority, medium priority, and high priority. In September 2014, supervisors of TIME $^{\mathrm{TM}}$ programs at 28 community centers were invited to complete an online questionnaire (Additional file 3) designed to characterize $\mathrm{TIME}^{\mathrm{TM}}$ program delivery.

Frequencies and percentages were used to summarize meeting and survey data. A descriptive content analysis [21] of the qualitative data from pre-meeting and meeting activities describing challenges to program implementation was performed. Similar challenges were clustered to identify themes.

\section{Results}

Of the 77 individuals invited, 53 (69\%) attended the meeting. Of the 53 attendees (positions and organizations are listed in Additional file 4), 21 (40\%) completed the pre-meeting activity, 40 (75\%) participated in discussions at stakeholder-specific tables of 6 stakeholder groups to identify challenges and solutions related to $\mathrm{TIME}^{\mathrm{TM}}$ program delivery, and 42 (79\%) rated the priority level of solutions post-meeting. Stakeholders who discussed program delivery challenges and solutions included 7 healthcare professionals, 9 healthcare system representatives, 11 fitness instructors, 9 recreation coordinators/managers, 3 researchers and 1 exercise participant.

Challenges identified during meeting discussions and voting results are described in Additional file 5. Challenges were captured by seven themes. (1) Resources to deliver the exercise class: Recreation centers faced issues related to inadequate space to run the class and store equipment and inappropriate exercise equipment. Recreation staff described difficulty finding instructors with the skills to work with people with multiple health conditions, language barriers, and low mobility levels, and to adapt the exercises to account for changes in participant ability or injury. Some centers were faced with high staff turnover; thus, maintaining a roster of trained staff 
over time was difficult. Recruiting, training and scheduling volunteers who were sometimes needed to maintain the 1:4 instructor-plus-volunteer-to-participant ratio was also noted as challenging. (2) Program marketing: Healthcare and recreation personnel recognised the challenge of promoting and raising awareness of the program among healthcare and rehabilitation professionals who could endorse the program and support referral to ensure adequate registration. (3) Transportation: Exercise participants and healthcare/recreation personnel agreed that transportation to the program could be costly and inconvenient. Adapted transport services did not consistently arrive on schedule, were cancelled during inclement weather, or were unavailable in rural areas. (4) Program access: Registration was not always possible. The program was either full or the exercises were inappropriate for some clients with multi-morbidities and low mobility levels and some clients with high functional levels who had already taken the program. These challenges were perceived as preventing long-term exercise participation. (5) Maintaining program integrity: This challenge related to ensuring consistent delivery of the program as intended over time across centers. (6) Sustaining partnerships: Maintaining roles, communication and collaboration between healthcare and recreation partners was considered challenging. (7) Funding: All stakeholders identified the need for additional funding to sustain the $\mathrm{TIME}^{\mathrm{TM}}$ program model. Recreation partners needed funding for staff wages, equipment, and program expansion; healthcare providers required funding to offer training and support; and clients needed funding to pay for program registration and transportation. Table 1 lists 29 strategies proposed to address the program challenges and associated priority ratings.

Seventeen supervisors of $\mathrm{TIME}^{\mathrm{TM}}$ programs run by 25 organizations in 28 community centers completed the online questionnaire (100\% response rate). Across 28 centers, TIME $^{\mathrm{TM}}$ programs had been running for $\leq 1$ year (14\%), $1-2$ years $(46 \%), 2-4$ years $(32 \%)$, and $6-8$ years (7\%). Exercises were performed in a circuit (original version) or three superstations (three exercises/superstation; updated version), in 57 and $29 \%$ of centers, respectively. Most frequently, classes were $60 \mathrm{~min}$ in length (89\%), provided twice a week (57\%) for 12 weeks (36\%), and 3 times per year (39\%). Volunteers and caregivers were permitted to assist in 75 and $89 \%$ of centers, respectively. Table 2 describes characteristics of program referral, advertisement, intake, format, and registration.

\section{Discussion}

This mixed methods study revealed a range of program challenges related to recreation center resources, program marketing, transportation, access, integrity, funding, and sustaining partnerships, relevant to six stakeholder groups. Stakeholders identified high priority strategies targeting each of these challenges, with the exception of transportation. These strategies can be used to inform the development of action plans to help implement and sustain the TIME ${ }^{\mathrm{TM}}$ program. Following spread of the TIME ${ }^{\mathrm{TM}}$ program to 28 community centers, certain recommended program elements, including class format and duration, participation of caregivers, involvement of and referral of participants by healthcare professionals, were maintained, while others, such as admission criteria, weekly class frequency, program duration, maximum class size, instructor-to-participant ratio, and use of volunteers, were adapted.

Some challenges to delivering the $\mathrm{TIME}^{\mathrm{TM}}$ program, such as program cost and transportation, have been noted previously by people with stroke [22-24], HIV [25], and COPD [26, 27], as primary barriers to participation in structured exercise programs. Individuals in these studies recommended making CBEP-HRPs widely available $[24,26]$. The ability to attend programs in close proximity to one's home was perceived to minimize travel time and cost of transportation, and offset the negative impact of unreliable public transit, and inclement weather on program attendance $[24,26]$. Subsidization of program cost was desired [26] as people with physical disability may be receiving a fixed income [25, 26]. Results from the current study further highlight the need for financial support of healthcare and recreation partners to sustain the CBEP-HRP model. The issue of program funding was recently investigated in a survey of providers of 14 exercise program programs for people with stroke in Scotland [28]. In this survey [28], three programs run by physiotherapists, nurses and assistants in healthcare settings to help transition people from hospital to independent exercise, were government-funded. Although participation was free, only one 10-week session was provided which may be insufficient to facilitate lifelong participation in physical activity. The strategy proposed in the current study to obtain regional healthcare funding for programs like TIME ${ }^{\mathrm{TM}}$ would provide people with physical disability with ongoing opportunities to exercise.

The importance of maintaining partnerships to sustain program referral, delivery, and integrity was underscored in our study. People with physical disability prefer a trusted healthcare practitioner to refer them to CBEPs, as this reassures them that the program is safe and appropriate [27]. Knowledge that a healthcare professional has continued involvement in a CBEP, as in the TIME ${ }^{\mathrm{TM}}$ program, provides further reassurance [29]. As proposed in the current study, standardized marketing materials used by a local facilitator may help foster partnerships with 


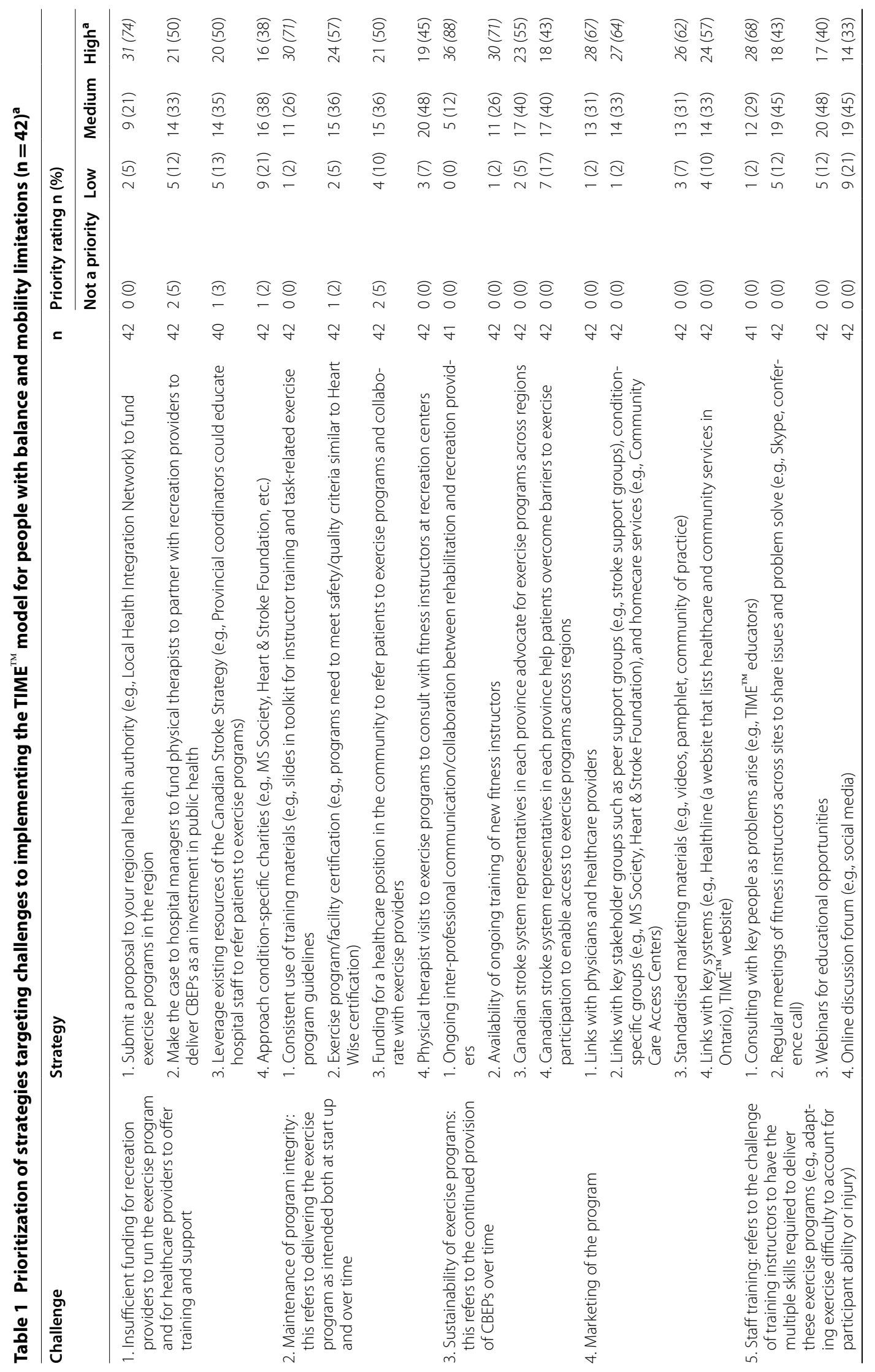




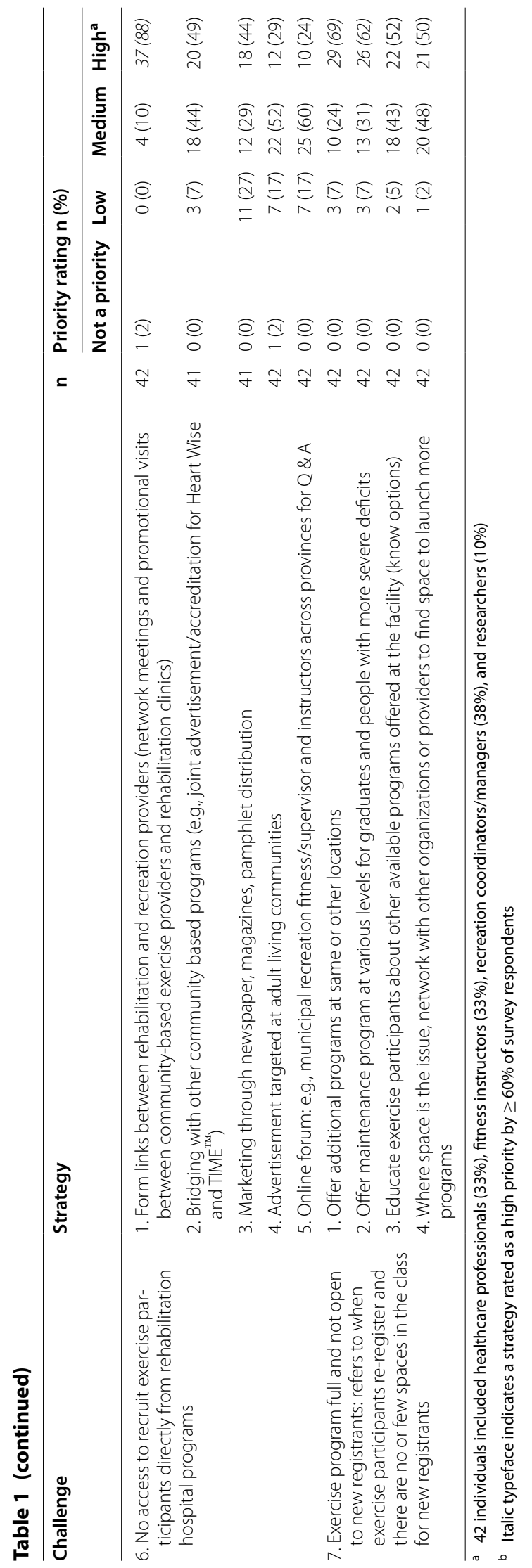


Table 2 Characteristics of TIME $^{\mathrm{TM}}$ programs at 28 community centers

\begin{tabular}{|c|c|c|}
\hline Program characteristic & No. responding ${ }^{a}$ & $\mathrm{n}(\%)$ \\
\hline \multicolumn{3}{|l|}{ Referral and advertisement } \\
\hline Referral by at least 1 hospital-based healthcare professional & $23 / 25$ & $23(100)$ \\
\hline Multi-program brochure & $24 / 25$ & $24(100)$ \\
\hline Website & $25 / 25$ & $24(96)$ \\
\hline Program-specific brochure & $24 / 25$ & $21(88)$ \\
\hline Free sessions offered to orient interested individuals & $23 / 25$ & $20(87)$ \\
\hline Charitable organizations & $23 / 25$ & $19(83)$ \\
\hline $\begin{array}{l}\text { Other (e.g., advertising in local homecare and physical therapy clinics, newspapers; local TV station interview; } \\
\text { visiting doctors' offices/hospitals) }\end{array}$ & $8 / 25$ & $4(50)$ \\
\hline \multicolumn{3}{|l|}{ Admission criteria } \\
\hline Able to walk $10 \mathrm{~m}$ independently \pm an assistive device & $25 / 25$ & $17(68)$ \\
\hline Self-reported balance or mobility limitation & $25 / 25$ & $17(68)$ \\
\hline Medical clearance form signed by physician or other provider & $24 / 25$ & $16(67)$ \\
\hline Other (e.g., PAR-Q+, medication form and waiver; no criteria) & $23 / 25$ & $3(13)$ \\
\hline \multicolumn{3}{|l|}{ Criterion to exclude based on high ability level } \\
\hline Able to walk 30 min continuously & $23 / 25$ & $7(30)$ \\
\hline No criteria & $23 / 25$ & $5(22)$ \\
\hline Other (e.g., ability to perform exercises easily in first class) & $23 / 25$ & $5(22)$ \\
\hline \multicolumn{3}{|l|}{ Conditions causing balance/mobility limitations in registrants } \\
\hline Stroke & $25 / 25$ & $25(100)$ \\
\hline Acquired brain injury & $24 / 25$ & $24(100)$ \\
\hline Multiple sclerosis & $20 / 25$ & $20(100)$ \\
\hline Parkinson's disease & $19 / 25$ & $18(95)$ \\
\hline Other (e.g., spinal cord injury, arthritis, frail elderly, cancer, and vertigo) & $19 / 25$ & $19(95)$ \\
\hline Typical number of participants per class & $28 / 28$ & \\
\hline $0-4$ & & $8(29)$ \\
\hline $5-8$ & & $8(29)$ \\
\hline $9-12$ & & $12(43)$ \\
\hline Maximum number of participants permitted per class & $28 / 28$ & \\
\hline $6-9$ & & $13(46)$ \\
\hline $10-12$ & & $9(32)$ \\
\hline $13-16$ & & $6(21)$ \\
\hline Minimum number of registrants to run a class & $28 / 28$ & \\
\hline $2-4$ & & $22(79)$ \\
\hline $5-8$ & & $4(14)$ \\
\hline $9-11$ & & $2(7)$ \\
\hline Typical number of instructors per class & $28 / 28$ & \\
\hline 1 instructor per class & & $5(18)$ \\
\hline 2 instructors per class & & $19(68)$ \\
\hline 3 instructors per class & & $1(4)$ \\
\hline Other [e.g., adding 1 instructor if class size $>6(n=2) ; 8-10$ volunteers $(n=1)$ ] & & $5(18)$ \\
\hline Typical number of volunteers per class & $28 / 28$ & \\
\hline 0 volunteers per class & & $9(32)$ \\
\hline 1 volunteer per class & & $10(36)$ \\
\hline 2 volunteers per class & & $3(11)$ \\
\hline$\geq 3$ volunteers per class & & $6(21)$ \\
\hline Typical instructor + volunteer-to-participant ratio & $27 / 28$ & \\
\hline$\leq 1: 4$ & & $22(81)$ \\
\hline$>1: 4$ (includes one center that reported 1:4-5) & & $5(19)$ \\
\hline
\end{tabular}


Table 2 (continued)

\begin{tabular}{|c|c|c|}
\hline Program characteristic & No. responding ${ }^{a}$ & n (\%) \\
\hline Typical number of caregivers per class & $28 / 28$ & \\
\hline 0 caregivers per class & & $4(14)$ \\
\hline 1 caregiver per class & & $8(29)$ \\
\hline 2 caregivers per class & & $10(36)$ \\
\hline Variable number, unable to specify. & & $6(21)$ \\
\hline Percentage of TIME ${ }^{\mathrm{TM}}$ participants that typically re-register (\%) & $28 / 28$ & \\
\hline 0 & & $1(4)$ \\
\hline $1-25$ & & $10(36)$ \\
\hline $26-50$ & & $2(7)$ \\
\hline $51-75$ & & $4(14)$ \\
\hline $76-100$ & & $11(39)$ \\
\hline Percentage of TIME ${ }^{\mathrm{TM}}$ participants typically unable to re-register as class is full (\%) & $26 / 28$ & \\
\hline 0 & & $6(23)$ \\
\hline $1-25$ & & $19(73)$ \\
\hline $26-50$ & & $0(0)$ \\
\hline $51-75$ & & $0(0)$ \\
\hline $76-100$ & & $1(4)$ \\
\hline $\mathrm{TIME}^{\mathrm{TM}}$ program has a waiting list ${ }^{\mathrm{b}}$ & $28 / 28$ & $11(39)$ \\
\hline Percentage of TIME ${ }^{\mathrm{TM}}$ participants that typically register for other exercise classes at the community center (\%) & $28 / 28$ & \\
\hline 0 & & $5(18)$ \\
\hline $1-25$ & & $17(61)$ \\
\hline $26-50$ & & $3(11)$ \\
\hline $51-75$ & & $0(0)$ \\
\hline $76-100$ & & $3(11)$ \\
\hline Exercise programs that $\mathrm{TIME}^{\mathrm{TM}}$ participants register for & $23 / 28$ & \\
\hline Pool classes & & $20(87)$ \\
\hline Yoga or chair yoga & & $9(39)$ \\
\hline Weight room programs & & $8(35)$ \\
\hline Gentle fit or seated fitness classes & & $6(26)$ \\
\hline Individual physical activity sessions & & $3(13)$ \\
\hline Tai chi & & $1(4)$ \\
\hline
\end{tabular}

a Denominator refers to either 25 organizations or 28 community centers

b Respondents reported having 5, 6, and 9 people on a waiting list for the $\mathrm{TIME}^{\mathrm{TM}}$ program

physicians, charities, peer support groups, and homecare service providers to help support program registration. Finally, opportunities for instructor training and continuing education, and the continued involvement of a healthcare provider in program delivery through periodic visits, may help to minimize local program adaptations that could decrease program quality and safety. For example, a third of centers in the current study did not apply the admission criteria of ability to walk 10 meters independently with or without an assistive device, considered a core program element [16]. This criterion helps to ensure participants have a minimum level of mobility to safely perform and benefit from the program exercises. Similarly, approximately $20 \%$ of centers reported a maximum class size of 14-16, and an instructor-to-participant ratio exceeding 1:4. These practices may reflect the inclusion of individuals with a higher level of balance and mobility ability that do not require close supervision. However, a ratio of 1:4 is important to ensure adequate supervision and participant safety. Future research should aim to better understand the role of healthcare providers in maintaining the safety and quality of CBEP-HRPs. Finally, CBEP-HRPs for individuals with more severe balance and mobility limitations as well as a process for graduating $\mathrm{TIME}^{\mathrm{TM}}$ program participants to more advanced exercise programs, were suggested to address wait lists observed in $39 \%$ of community centres offering the $\mathrm{TIME}^{\mathrm{TM}}$ program and enable exercise participation for a larger group of individuals. 


\section{Conclusions}

Stakeholders involved in the unplanned spread of the CBEP-HRP TIME $^{\mathrm{TM}}$ model in a publicly-funded healthcare system encounter challenges related to inadequate funding and infrastructure that may threaten the sustainability of these programs. Local application of the solutions proposed in this research is likely to result in slow and haphazard improvements as it will depend on the resources of individual organizations. Public health agencies, supported by a mandate and dedicated funding, will find our study findings relevant to planning for systematic development and scale-up of CBEP-HRPs to enable widespread and equitable access to exercise participation for people with a wide range of balance and mobility limitations.

\section{Limitations}

Challenges and strategies identified in this study may primarily reflect the priorities of healthcare and recreation professionals as they had a high degree of representation. Their opinions, however, were informed by presentations made by exercise participants and caregivers early in the meeting. Seating participants by stakeholder group and inclusion of anonymous voting were strengths of the meeting process that helped to ensure representation of multiple stakeholder perspectives.

\section{Additional files}

\author{
Additional file 1. Pre-meeting Activity. \\ Additional file 2. Meeting Agenda. \\ Additional file 3. TIME ${ }^{\mathrm{TM}}$ Survey Questionnaire. \\ Additional file 4. Meeting participant positions and organizations. \\ Additional file 5. Identification and endorsement of challenges.
}

\section{Abbreviations \\ CBEP: community-based exercise program; CBEP-HRP: community-based exercise program incorporating a healthcare-recreation partnership; TIME $^{\mathrm{TM}}$ : Together in Movement and Exercise.}

\section{Authors' contributions}

NMS, JH, DB and SM conceptualised the paper. NMS summarized the results of the knowledge translation meeting. NMS, SM and SEPM analysed the data. All authors interpreted the data and revised the manuscript critically for important intellectual content. All authors read and approved the final manuscript.

\section{Author details}

${ }^{1}$ Department of Physical Therapy, University of Toronto, 160-500 University Avenue, Toronto, ON M5G 1V7, Canada. ${ }^{2}$ University Health Network-Toronto Rehabilitation Institute, 550 University Avenue, Toronto, ON M5G 2A2, Canada.

\section{Acknowledgements}

Authors would like to acknowledge the stakeholders that participated in the meeting and completed the online questionnaires.

\section{Competing interests}

Authors NMS, JH and SEPM are affiliated with the Toronto Rehabilitation Institute-University Health Network which licenses recreation providers to deliver the TIME ${ }^{\mathrm{TM}}$ program. Author $\mathrm{JH}$ developed the TIME ${ }^{\mathrm{TM}}$ program and the toolkit. None of the authors derives financial gain from the TIME ${ }^{\mathrm{TM}}$ program.

\section{Availability of data and materials}

A qualitative dataset was not generated for this study due to the nature of the data collection. Quantitative data will not be available due to privacy issues.

\section{Consent for publication \\ Not applicable.}

\section{Ethics approval and consent to participate}

The University of Toronto Health Sciences Research Ethics Board waived the requirement for ethics approval given that meeting activities were not conducted for research purposes. All individuals provided written consent via email to attend the meeting with the exception of select exercise participants and caregivers who provided verbal consent.

\section{Funding}

The Canadian Institutes of Health Research provided a grant to conduct the meeting and online surveys and a salary award to support NMS. The Government of Ontario provided funding to support SM to conduct data analysis and reporting.

\section{Publisher's Note}

Springer Nature remains neutral with regard to jurisdictional claims in published maps and institutional affiliations.

Received: 11 November 2017 Accepted: 21 March 2018

Published online: 02 April 2018

\section{References}

1. Mayo NE, Wood-Dauphinee S, Côté R, Durcan L, Carlton J. Activity, participation, and quality of life 6 months poststroke. Arch Phys Med Rehabil. 2002;83:1035-42.

2. Matsuda PN, Shumway-Cook A, Bamer AM, Johnson SL, Amtmann D, Kraft GH. Falls in multiple sclerosis. PMR. 2011;3:624-32.

3. DePaul VG, Moreland JD, Dehueck AL. Physiotherapy needs assessment of people with stroke following discharge from hospital, stratified by acute functional independence measure score. Physiother Can. 2013;65:204-14.

4. Michael KM, Allen JK, Macko RF. Reduced ambulatory activity after stroke: the role of balance, gait, and cardiovascular fitness. Arch Phys Med Rehabil. 2005;86:1552-6.

5. Booth FW, Roberts CK, Laye MJ. Lack of exercise is a major cause of chronic diseases. Compr Physiol. 2012;2:1143-211.

6. Reddigan II, Ardern Cl, Riddell MC, Kuk JL. Relation of physical activity to cardiovascular disease mortality and the influence of cardiometabolic risk factors. Am J Cardiol. 2011;108:1426-31.

7. Sari N. Exercise, physical activity and healthcare utilization: a review of literature for older adults. Maturitas. 2011;70:285-9.

8. Wiles R, Demain S, Robison J, Kileff J, Ellis-Hill C, McPherson K. Exercise on prescription schemes for stroke patients post-discharge from physiotherapy. Disabil Rehabil. 2008;30:1966-75.

9. Cramp MC, Greenwood RJ, Gill M, Lehmann A, Rothwell JC, Scott OM. Effectiveness of a community-based low intensity exercise programme for ambulatory stroke survivors. Disabil Rehabil. 2010;32:239-47.

10. Harrington R, Taylor G, Hollinghurst S, Reed M, Kay H, Wood VA. A community-based exercise and education scheme for stroke survivors: a randomized controlled trial and economic evaluation. Clin Rehabil. 2010;24:3-15.

11. Reed M, Harrington R, Duggan A, Wood VA. Meeting stroke survivors' perceived needs: a qualitative study of a community-based exercise and education scheme. Clin Rehabil. 2010;24:16-25.

12. Elsworth C, Winward C, Sackley C, Meek C, Freebody J, Esser P, et al. Supported community exercise in people with long-term 
neurological conditions: a phase II randomized controlled trial. Clin Rehabil. 2011;25:588-98.

13. Winward C, Sackley C, Meek C, Izadi H, Barker K, Wade D, et al. Weekly exercise does not improve fatigue levels in Parkinson's disease. Mov Disord. 2012;27:143-6.

14. Hassett LM, Moseley AM, Tate RL, Harmer AR, Fairbairn TJ, Leung J. Efficacy of a fitness centre-based exercise programme compared with a home-based exercise programme in traumatic brain injury: a randomized controlled trial. J Rehabil Med. 2009:41:247-55.

15. Stuart M, Benvenuti F, Macko R, Taviani A, Segenni L, Mayer F, et al. Community-based adaptive physical activity program for chronic stroke: feasibility, safety, and efficacy of the Empoli model. Neurorehabil Neural Repair. 2009;23:726-34.

16. Salbach NM, Howe JA, Brunton K, Salisbury K, Bodiam L. Partnering to increase access to community exercise programs for people with stroke, acquired brain injury, and multiple sclerosis. J Phys Act Health. 2014;11:838-45.

17. Foster ER, Golden L, Duncan RP, Earhart GM. Community-based Argentine tango dance program is associated with increased activity participation among individuals with Parkinson's disease. Arch Phys Med Rehabil. 2013;94:240-9.

18. Merali S, Cameron Jl, Barclay R, Salbach NM. Characterising community exercise programmes delivered by fitness instructors for people with neurological conditions: a scoping review. Health Soc Care Community. 2016;24:e101-16.

19. Together in Movement and Exercise (TIME $\left.{ }^{\mathrm{TM}}\right)$. http://www.uhn.ca/Toron toRehab/PatientsFamilies/Clinics_Tests/TIME. 2018. Accessed 05 Jan 2018.

20. Howe JA, Brunton K. Implementing a community-based exercise program for people with balance and mobility challenges: a step-by-step toolkit, vol. 2. Toronto: University Health Network—-Toronto Rehabilitation Institute; 2015.
21. Hsieh HF, Shannon SE. Three approaches to qualitative content analysis. Qual Health Res. 2005;15:1277-88.

22. Nicholson SL, Donaghy M, Johnston M, Sniehotta FF, van Wijck F, Johnston $\mathrm{D}$, et al. A qualitative theory guided analysis of stroke survivors' perceived barriers and facilitators to physical activity. Disabil Rehabil. 2014;36:1857-68.

23. Morris JH, Oliver T, Kroll T, Joice S, Williams B. From physical and functional to continuity with pre-stroke self and participation in valued activities: a qualitative exploration of stroke survivors', carers' and physiotherapists' perceptions of physical activity after stroke. Disabil Rehabil. 2015;37:64-77.

24. Blonski DC, Covert M, Gauthier R, Monas A, Murray D, O'Brien KK, et al. Barriers to and facilitators of access and participation in communitybased exercise programmes from the perspective of adults with poststroke aphasia. Physiother Can. 2014;66:367-75.

25. Li A, McCabe T, Silverstein E, Dragan S, Salbach NM, Zobeiry M, et al. Community-based exercise in the context of HIV: factors to consider when developing and implementing community-based exercise programs for people living with HIV. J Int Assoc Provid AIDS Care. 2017;16:267-75.

26. Desveaux L, Rolfe D, Beauchamp M, Goldstein R, Brooks D. Participant experiences of a community-based maintenance program post-pulmonary rehabilitation. Chronic Respir Dis. 2014;11:23-30.

27. Thorpe O, Johnston K, Kumar S. Barriers and enablers to physical activity participation in patients with COPD: a systematic review. J Cardiopulm Rehabil Prev. 2012;32:359-69.

28. Best C, van Wijck F, Dennis J, Smith M, Donaghy M, Fraser H, et al. A survey of community exercise programmes for stroke survivors in Scotland. Health Soc Care Community. 2012;20:400-11.

29 Elsworth C, Dawes H, Sackley C, Soundy A, Howells K, Wade D, et al. A study of perceived facilitators to physical activity in neurological conditions. Int J Ther Rehabil. 2009:16:17-24.

\section{Submit your next manuscript to BioMed Central and we will help you at every step:}

- We accept pre-submission inquiries

- Our selector tool helps you to find the most relevant journal

- We provide round the clock customer support

- Convenient online submission

- Thorough peer review

- Inclusion in PubMed and all major indexing services

- Maximum visibility for your research

Submit your manuscript at www.biomedcentral.com/submit 